\title{
Future High-Performance Spaceborne Microwave Radiometer Systems
}

\author{
Skou, Niels; Søbjerg, Sten S.; Kristensen, Steen S.
}

Published in:

Proceedings of the 2020 16th Specialist Meeting on Microwave Radiometry and Remote Sensing of the Environment (MicroRad)

Link to article, DOI:

10.1109/MicroRad49612.2020.9342542

Publication date:

2020

Document Version

Publisher's PDF, also known as Version of record

Link back to DTU Orbit

Citation (APA):

Skou, N., Søbjerg, S. S., \& Kristensen, S. S. (2020). Future High-Performance Spaceborne Microwave Radiometer Systems. In Proceedings of the 2020 16th Specialist Meeting on Microwave Radiometry and Remote Sensing of the Environment (MicroRad) IEEE. https://doi.org/10.1109/MicroRad49612.2020.9342542

\section{General rights}

Copyright and moral rights for the publications made accessible in the public portal are retained by the authors and/or other copyright owners and it is a condition of accessing publications that users recognise and abide by the legal requirements associated with these rights.

- Users may download and print one copy of any publication from the public portal for the purpose of private study or research.

- You may not further distribute the material or use it for any profit-making activity or commercial gain

- You may freely distribute the URL identifying the publication in the public portal 


\section{Future High-Performance Spaceborne Microwave Radiometer Systems}

\author{
Niels Skou \\ DTU Space \\ Technical University of Denmark \\ DK 2800 Lyngby, Denmark \\ ns@space.dtu.dk
}

\author{
Sten S. Søbjærg \\ DTU Space \\ Technical University of Denmark \\ DK 2800 Lyngby, Denmark \\ sss@space.dtu.dk
}

\author{
Steen S. Kristensen \\ DTU Space \\ Technical University of Denmark \\ DK 2800 Lyngby, Denmark \\ ssk@space.dtu.dk
}

\begin{abstract}
In a traditional spaceborne microwave radiometer system with a scanning antenna there is often a conflict between spatial and radiometric resolution. Integration over many beams per frequency might be necessary to improve radiometric resolution. Many beams may be generated using many classical feed horns or by a Focal Plane Array (FPA) system. At $\mathrm{C}$-band horns are bulky and replacing several such horns with a FPA is an interesting option.
\end{abstract}

Keywords-microwave; radiometer; focal plane array; receiver

\section{INTRODUCTION}

New and challenging spaceborne microwave radiometer systems, encompassing the classical frequencies from Cband through $\mathrm{Ka}$-band, are presently being considered by the space agencies. Compared to present systems, requirements to spatial resolution and radiometric resolution are significantly tougher, and beam quality (polarization purity, land-sea-contamination) is also an important issue.

To fulfill spatial resolution requirements, antenna apertures approaching $10 \mathrm{~m}$ are considered. Tough requirements to both spatial and radiometric resolution leads to a conflicting situation due to a small dwell time per footprint, and the only remedy is to integrate over many antenna beams per frequency. Thus we need several classical feed horns with associated classical receivers, or we can go for a focal plane array (FPA) system. In an FPA system many small feed elements (could be 30) illuminate the antenna reflector and by properly adding the output of each element in amplitude and phase, a number of almost perfect antenna beams can be generated [Iupikov et al, 2018], [Skou et al, 2019].

Classical horns and associated receivers are well known meaning low development risk - an important issue in all space projects. The FPA system is a new concept that have never flown, but only studied theoretically, and antenna breadboards have been evaluated. An obvious challenge is that the system may employ 30 receives, 30 fast analog to digital converters (ADC) (the full RF bandwidth must be digitized), as well as significant and fast digital processing hardware - all on-board and real time. This means development risk.

The new system may combine the two options: $\mathrm{C}$ and $\mathrm{X}$ bands could use FPA, while the higher frequencies rely on classical horns. This seems an interesting combination since there will be technology challenges for the FPA system at high frequencies, while the FPA can replace big horns at low frequencies. Such a system has been considered where 4 relatively big C-band horns are replaced by an A4 sized FPA system producing again 4 beams. In the following we will discuss a first order design of such a system especially focusing on power resource issues for the FPA system.

\section{SYSTEM ASSUMPTIONS AND RELATIONS}

Users of multi-frequency radiometer data have for years been served by the AMSR type of data, having a spatial resolution of $\approx 50 \mathrm{~km}$ at $\mathrm{C}$-band and $\approx 20 \mathrm{~km}$ at Ku band. Now more ambitious systems are being studied, opting for: $\approx$ $15 \mathrm{~km}$ at $\mathrm{C}$-band and $\approx 5 \mathrm{~km}$ at $\mathrm{Ku}$ band. At the same time improved radiometric resolution is highly warranted. So, we are talking about a 4 times bigger antenna: from the $1.6-1.8$ $\mathrm{m}$ range to the $7 \mathrm{~m}$ range, and more sensitive receivers or in practice integration over several antenna beams.

As an example we will in the following study a system with conically scanning by a rotating antenna, see Fig. 1 . The satellite altitude is a typical $817 \mathrm{~km}$ and the incidence angle a typical $55^{\circ}$. The antenna temperature is assumed to be $150 \mathrm{~K}$ (between sea and land). The footprint (FP) is the intersection between a plane Earth surface and the antenna beam at $-3 \mathrm{~dB}$ level. The single value for FP is the mean of the footprint along track (FPL) and across track (FPS). 20\% FP overlap is assumed both across track and along track to avoid aliasing in the sampling process.

Channel specifications and requirements are shown in Table I. The maximum bandwidth (BW) indicates RFI benign conditions, but the realistic bandwidth is used in the following. $\Delta \mathrm{T}$ is the radiometric resolution.

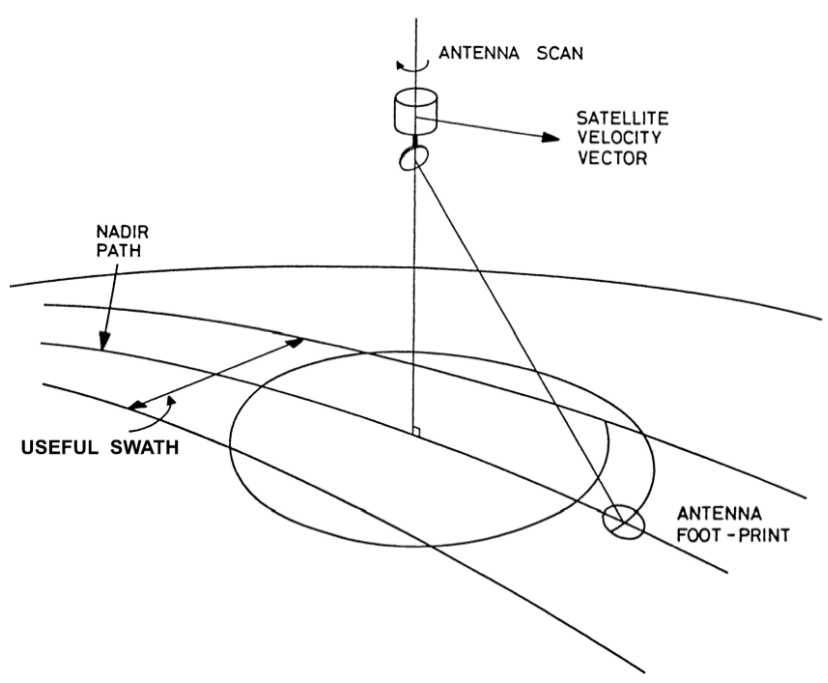

Fig. 1. Typical Scanner Situation 
TABLE I. RADIOMETRIC SPECIFICATIONS

\begin{tabular}{|l|c|c|c|c|}
\hline Frequency $(\mathrm{GHz})$ & 6.925 & 10.65 & 18.7 & 36.5 \\
\hline Max BW (MHz) & 350 & 100 & 200 & 1000 \\
\hline Realistic BW & 300 & 90 & 180 & 300 \\
\hline FP $(\mathrm{km})$ goal & 15 & 10 & 5 & 3 \\
\hline$\Delta \mathrm{T}(\mathrm{K})$ req. & 0.2 & 0.3 & 0.3 & 0.7 \\
\hline
\end{tabular}

Now calculation of important parameters like antenna size, integration time $\tau$, antenna rotations per minute (RPM), and $\Delta \mathrm{T}$ can be carried out as illustrated in Table II. As an example $\mathrm{Ku}$ band is shown.

It is seen that in order to fulfill the required $5 \mathrm{~km}$ footprint, an antenna with an $\approx 8 \mathrm{~m}$ reflector is required. This is in itself a technical challenge, but at the same time we note a far from satisfactory $\Delta \mathrm{T}$ and a large RPM far from acceptable. Several beams per frequency are required in order to improve $\Delta \mathrm{T}$ by integration and to lower the RPM.

Strict fulfillment of specifications leads to:

- 4 beams along track @ C-band, $\Delta \mathrm{T}=0.13 \mathrm{~K}$

- 6 beams along track@ $@$-band, $\Delta \mathrm{T}=0.36 \mathrm{~K}$

- 12 beams along + 2 beams across track @ Ku band, $\Delta \mathrm{T}=$ $0.30 \mathrm{~K}$

- 20 beams along track @ Ka band, $\Delta \mathrm{T}=0.48 \mathrm{~K}$

- 6.5 RPM

We note that a great many beams (hence receivers) are needed especially at the higher frequencies. Typically, there will now be discussions between the instrument provider and the data users in order to ensure a reasonable complexity and cost while still providing usable data. One might relax on footprint overlap, spatial resolution, radiometric resolution at certain frequencies.

Here we assume that such discussions have lead to a viable system at all frequencies, technical solutions have been found, and concentrate on C-band requiring 4 beams. Classical C-band feed horns are large and bulky, and we will now consider a FPA solution.

TABLE II. PARAMETER RELATIONS - KU BAND

\begin{tabular}{|c|c|c|c|c|c|c|c|}
\hline$H(\mathrm{~km})=$ & 817 & inc angl = & & 0,95975 & & FP overlap- & 0,8 \\
\hline \multirow[t]{2}{*}{$F(\mathrm{GHz})=$} & 18,7 & $T A(K)=$ & 150 & $T N(K)=$ & 238 & $\mathrm{~B}(\mathrm{MHz})=$ & 180 \\
\hline & Calculations: & & & & & & \\
\hline $\sin \alpha=0$ & 072604436 & & 581255102 & & & & \\
\hline \multirow{3}{*}{$\begin{array}{l}\gamma=0 \\
Y=\end{array}$} & 0,14720 & & & & & & \\
\hline & 1288,40982 & $x=$ & 935,442688 & $r=$ & 7195 & VSSP= & 6,61215423 \\
\hline & Results: & & & & & & \\
\hline$D(m)$ & FPS $(\mathrm{km})$ & $F P L(\mathrm{~km})$ & $F P(\mathrm{~km})$ & & $\tau$ (msec) & RPM & $\Delta T(K)$ \\
\hline 3 & 965 & 1681 & 1323 & & 27 & 295 & $056-2-1$ \\
\hline 4 & 7,23 & 12,61 & 9,92 & & 1,5 & 39,3 & 0,75 \\
\hline 5 & 5,79 & 10,09 & 7,94 & & 1,0 & 49,2 & 0,93 \\
\hline 6 & 4.82 & 8.41 & 6.61 & & 07 & 590 & 1.12 \\
\hline 6,7 & 4,32 & 7,53 & 5,92 & & 0,5 & 65,9 & 1,25 \\
\hline 7 & 4,13 & 7.21 & 5.67 & & 0.5 & 68.8 & 1.31 \\
\hline 7,9 & 3,66 & 6,38 & 5,02 & & 0,4 & 77,7 & 1,47 \\
\hline 8 & 3,62 & 6,30 & 4,96 & & 0.4 & 78,7 & 1,49 \\
\hline 9 & 3,22 & 5,60 & 4,41 & & 0,3 & 88,5 & 1,68 \\
\hline 10 & 289 & 5.04 & 3.97 & & 02 & 98.3 & 187 \\
\hline
\end{tabular}
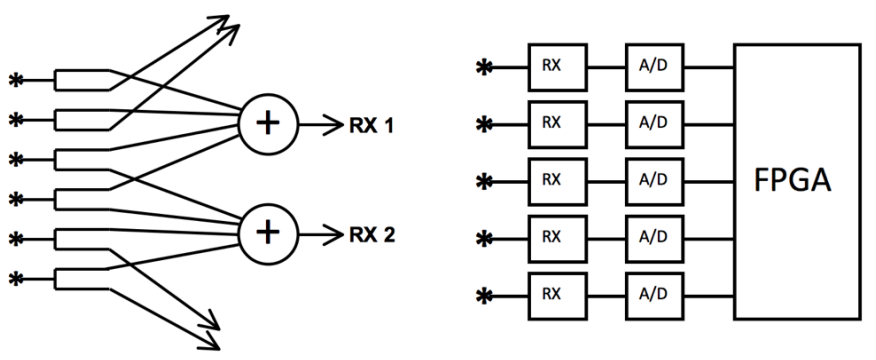

Fig. 3. Dense Array Receiver System
In a traditional system a feed horn is connected to the receiver via some kind of calibration system, see Fig. 2, left.

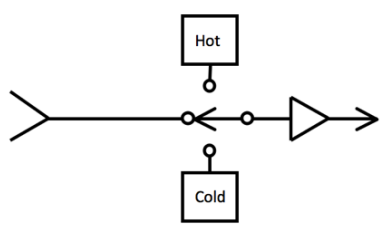

RX:

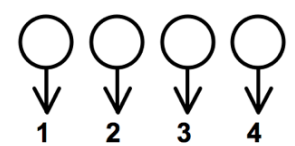

Multi beam / RX system

Traditional, single beam system

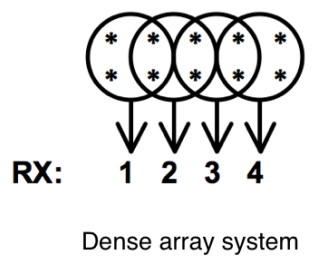

Fig. 2. Classical Feed Horn $+\mathrm{RX}$ and Focal Plane Array System

In our C-band system we need 4 of these as illustrated in Fig. 2, right, top. In the FPA system we use many small, closely spaced antenna elements, and sum the output from a number of them to provide one antenna beam similar to that of the traditional feed horn, see Fig. 2, right, bottom. That summation is illustrated in Fig. 3, left where the small antenna elements for practical reasons are shown on one line. Power splitters and summers in principle do the job. For signal loss reasons this will not work, and we have to go to Fig. 3 right, where it is seen that the outputs of the antenna elements are individually connected to as many receivers, the full bandwidth is A to D converted, and finally summed in phase and amplitude in a fast Field Programmable Gate Array (FPGA).

The C-band system is shown in more detail in Fig. 4. The 4 traditional horns are seen in positions such that the required $20 \%$ footprint overlap results. The horns are quite large having a diameter of about $22 \mathrm{~cm}$ (and a significant length), while the FPA is of A4 size (and quite flat). In Fig. 4 the FPA consist of 35 antenna elements, and something like that is suited for 4 beams. 

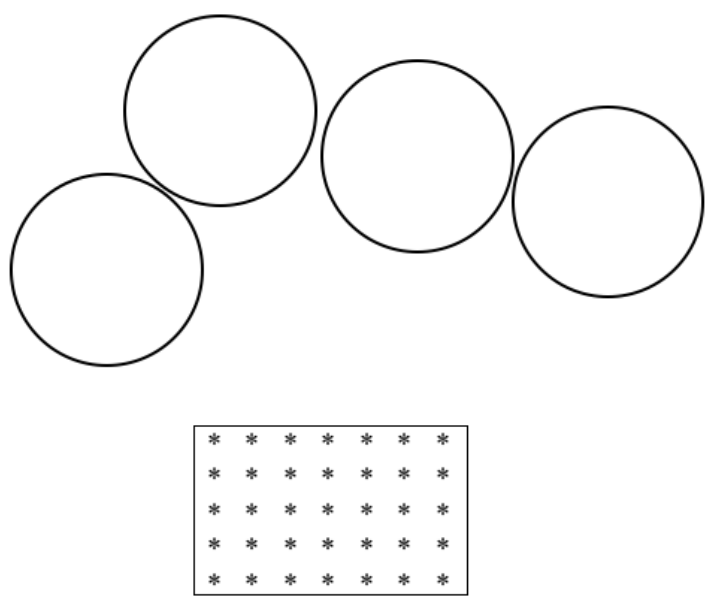

Fig. 4. C-band Antenna Elements. Horn diameter $\approx 22 \mathrm{~cm}$.

\section{FPA RECEIVER DESIGN AND POWER BUDGET}

The receivers are designed according to the superheterodyne principle thus enabling a flexible IF frequency to fit the ADC's, see Fig. 5. The input switch can select a reference noise signal from a central noise diode in order to validate coherence between all the receivers. The switch can also select hot or cold calibration points in the form of a matched load (HL) or an active cold load (ACL). The switch is followed by suitable amplifiers and a mixer. This is fed from a central local oscillator (LO) common for all receivers.

Several component types have been considered: switch, low-noise amplifier, mixer, local oscillator, IF amplifier, and especially ADC. No search for space qualified components or fancy, new laboratory developments has been made - just small, low noise commercially available components have been considered.

All components are of the MMIC type or similar being very small and low weight. Hence, weight and bulk is no issue, and only power will be dealt with in the following.

Relevant components are:

- Input switch: MA4AGSSW4, L through X bands, 0.4 $0.6 \mathrm{~dB}$ loss, very little power.

- Mixer: powered by LO circuitry.

- Oscillator: $300 \mathrm{~mW}$

- A range of amplifiers, see Table III.

The table shows also $\mathrm{X}$-band amplifiers since it is possible to design an FPA able to handle both $\mathrm{C}$ and $\mathrm{X}$ bands. This is not dealt with is the present paper.

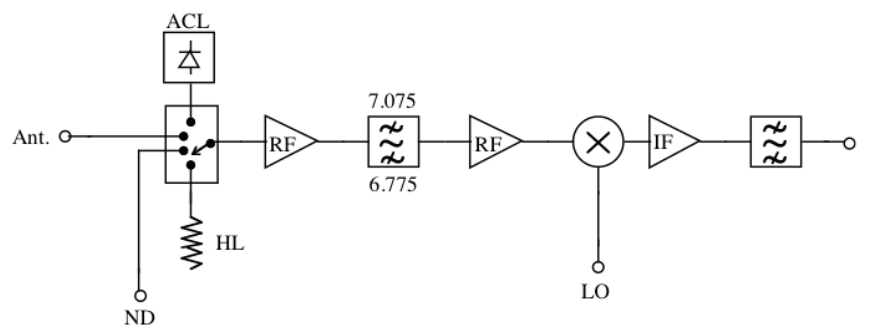

Fig. 5. C-band receiver (X-band similar)
TABLE III. COMMERCIALly AVAILABLE COMPONENTS

\begin{tabular}{|c|c|c|c|c|}
\hline Frequency & Type & $\begin{array}{c}\text { NF } \\
\mathrm{dB}\end{array}$ & $\begin{array}{c}\text { Gain } \\
\mathrm{dB}\end{array}$ & $\begin{array}{c}\text { Power } \\
\mathrm{mW}\end{array}$ \\
\hline IF $(100-300 \mathrm{MHz})$ & GALI-S66 & & 20 & 60 \\
\hline $\mathrm{C}$ & CGY2120 & 0.6 & 13 & 50 \\
\hline $\mathrm{X}$ & CGY2124 & 1.2 & 33 & 275 \\
\hline $\mathrm{C}$ and $\mathrm{X}$ & TGA2600 & 0.7 & 30 & 45 \\
\hline
\end{tabular}

The CGY amplifiers are from OMMIC, the GALI from Mini-Circuits, and the TGA from TriQuint. The gains of these amplifiers are such that the C-band receiver (in addition to one pre-amp) needs $3 \mathrm{RF}$ amplifiers in series and 2 IF amplifiers in series.

A realistic power budget for one C-band receiver can now be established as follows:

- 1 RF C-band pre-amp

$50 \mathrm{~mW}$

- 3 x RF C-band amps each $50 \mathrm{~mW}$

$150 \mathrm{~mW}$

- 2 x IF amps each $60 \mathrm{~mW}$

$120 \mathrm{~mW}$

- 1 ACL (low-noise pre-amp) $50 \mathrm{~mW}$

- In total per receiver

$370 \mathrm{~mW}$

Previously, it has been stated that an FPA able to create 4 beams typically will have some 30 elements. In the present design we have considered 32 elements. Since we typically consider dual polarization systems, this means 64 receivers.

\section{- In total for the $\mathrm{C}$-band receivers}

$24 \mathrm{~W}$

Concerning the local oscillator system, we need $10 \mathrm{~mW}$ per mixer. We have 64 mixers i.e. 0.01 x $64=0.6 \mathrm{~W}$. The signals for the mixers are generated in an oscillators using $300 \mathrm{~mW}$, followed by amplification. Assuming an amplifier efficiency of $50 \%$ this means that

\section{- In total for the local oscillator circuitry}

$2 \mathbf{W}$

The noise injection calibration circuitry contributes by an insignificant amount.

The beam-forming network is based on the powerful Zynq UltraScale+ RFSoC FPGA that includes 16 each 2 GSPS 12-bit ADCs. Analog bandwidth is $4 \mathrm{GHz}$, and the estimated power consumption is $\approx 20 \mathrm{~W}$. The C-band system requires 4 FPGAs each consuming about $20 \mathrm{~W}$. Thus we find:

- Initial total for ADC and beam forming

$80 \mathrm{~W}$

Thus, the first estimate for the receivers, local oscillator circuitry, calibration, and beam forming is:

- Initial total for the C-band system

$106 \mathrm{~W}$

However, this is far from using the full potential of the FPGA and especially the potential of its ADCs. The receiver bandwidth is only $300 \mathrm{MHz}$ while the ADCs can operate with 2 GSPS. One antenna element requires 2 receivers (for $\mathrm{H}$ and $\mathrm{V}$ polarization). The local oscillator frequency for the $\mathrm{H}$ channel is set to $6.675 \mathrm{GHz}$ and the $\mathrm{LO}$ for $\mathrm{V}$ is set to $6.275 \mathrm{GHz}$. The $2 \mathrm{IF}$ outputs are added and fed into one ADC. Frequencies are: $100-400 \mathrm{MHz}$ and $500-800 \mathrm{MHz}$. Later in the system the two channels are separated again digitally. A sampling frequency of $1.7 \mathrm{GHz}$ is assumed. Thus 
the C-band system requires only 2 FPGAs each consuming about $20 \mathrm{~W}$. Thus we find:

\section{- Total for ADC and beam forming}

$40 \mathrm{~W}$

It should be noted, however, that a slightly more complicated LO system is now required since we need two separate LO frequencies $(6.675 \mathrm{GHz}$ and $6.275 \mathrm{GHz})$. This does no affect power consumption significantly, and we can still stay within the $2 \mathrm{~W}$ allocated in the budget. But bulk and complexity are enhanced by having two independent LO distribution networks.

Thus, the first estimate for the receivers, local oscillators, calibration, beam-forming, is:

\section{- Power consumption for the C-band system $66 \mathrm{~W}$}

(It should be noted here that the resources in the FPGA are so large that probably there is actually room for an RFI processor, which otherwise consumes an appreciable amount of power. This is, however, not established yet, and requires further studies).

\section{SUMMARY}

The focal plane array kind of antenna feed system may offer an interesting alternative to the classical feed horn. One array can generate several antenna beams thus substituting several horns. This is interesting at the higher microwave frequencies where a large number of beams may be needed (see the references), but it also of interest at the lower microwave frequencies like C-band, where large and bulky horns may be replaced by a relatively small focal plane array system.

The price to pay is: no flight heritage, and slightly increased power consumption. The present paper has discussed a C-band system in which 4 classical horns are replaced by a focal plane array having 32 antenna elements and 64 receivers (dual polarization operation). The power consumption is estimated to $66 \mathrm{~W}$, which is more than a classical radiometer solution requires, but very far from critical in modern satellite systems.

\section{ACKNOWLEDGMENT}

The work described in this paper was supported by and carried out in cooperation with TICRA A/S, Copenhagen.

\section{REFERENCES}

[1] Iupikov, O. A., Ivashina, M. V., Skou, N., Cappellin, C., Pontoppidan, K. \& van 't Klooster, K.: "Multi-Beam Focal Plane Arrays with Digital Beamforming for High Precision Space-Borne Ocean Remote Sensing", IEEE Trans. on Antennas and Propagation, Vol. 66, No. 2, Feb. 2018, pp $737-748$

[2] N. Skou, S. S. Søbjærg, S. S. Kristensen, C. Cappellin, K. Pontoppidan, J. R. de Lasson, M. Ivashina, and O. Iupikov: "UltraHigh Performance C \& L-Band Radiometer System for Future Spaceborne Ocean Missions", IEEE Journal Sel. Topics Appl. Earth Observ. and Remote Sensing, Vol 12, No 6, June 2019, pp 1670 1678 